\title{
EFFECTS OF MUSCLE STRENGTH EXERCISE PROTOCOLS ON POST- EXERCISE HYPOTENSION IN ELDERLY
}

\author{
Lucas do C. Santos (IC), Amanda V. Sardeli (PG), Marina Lívia V. Ferreira (PG), Arthur F. Gáspari \\ (PG), Cláudia R. Cavaglieri (PQ), José Rocha (PQ), Mara Patrícia T. Chacon-Mikahil (PQ) \\ Resumo
}

The present study analyzed systolic, diastolic and mean arterial blood pressure after different strength exercise (SE, performed in leg press machine) protocols, which according to literature are efficient to increase strength and muscle mass in healthy elderly. The study was performed in a cross-over design, containing the following sessions: SEHI ( $80 \% 1 \mathrm{RM}$, 4 sets with repetitions until voluntary failure), SEBFR ( $30 \% 1 \mathrm{RM}, 1$ set of 30 repetitions plus 3 sets of 15 repetitions, with $50 \%$ blood flow restriction), SELO ( $30 \%$ $1 \mathrm{RM}, 4$ sets with repetitions until voluntary failure) and control (no exercise). The data showed blood pressure variation from pre to post-exercise $(5,15$ and 30 minutes) did not differ between SE sessions. Regarding these acute blood pressure variations, none of the SE protocols applied showed to be more beneficial or harmful to the cardiovascular system.

Palavras Chave: strength exercise, blood pressure, aging.

\section{Introdução}

Structural and functional physiological changes inherent to the aging process contribute to elevated blood pressure (BP). The high BP levels increases the risk for diseases and cardiovascular events, being the maintenance of normal BP is primordial to the health. Post-exercise hypotension $(\mathrm{PEH})$ is the $\mathrm{BP}$ reduction during the recovery period, below baseline levels. Studies have shown there is a strong association between $\mathrm{PEH}$ and the chronic reduction of the BP. Thus, since the PEH is an important effect of exercise regarding improved cardiovascular health, the present study compared the effect of three different strength training protocols, found to be effective gain strength and muscle mass, on the $\mathrm{PEH}$.

\section{Resultados e Discussão}

Eighteen unmedicated and normotensive elderly (BP mean 129/71 $\pm 15.8 / 5.8 \mathrm{mmHg}$ ) participated in the study (10 women, 8 men, $64.3 \pm 4.5$ years, $68.6 \pm 12.7 \mathrm{~kg}$ and $163.1 \pm 7.8 \mathrm{~cm}$ ) after clinical trial, familiarization with the protocols and assessment of maximum strength of the lower limbs in leg-press (1RM). The study was conducted in a cross-over design, with a minimum interval of 96 hours among the following sessions of strength exercises: SEHI (80\% 1RM, 4 sets with repetitions until voluntary failure), SEBFR ( $30 \% 1 \mathrm{RM}, 1$ set 30 reps +3 sets of 15 repetitions with $50 \%$ of blood flow restriction) and SELO $(30 \% 1 \mathrm{RM}, 4$ sets with repetitions until voluntary failure), besides the CONTROL session (no exercise). ANOVA two way was applied to compare the BP deltas of every moment of recovery in relation to pre exercise, between the different protocols. There were no differences between pre exercise values and the deltas of 5 , 15 and 30 minutes of recovery for systolic BP, diastolic BP and mean BP between the applied strength exercise sessions. In addition, analyzing the individual variations of BP in each exercise session, we observed a great variability of responses, which part of individuals increased and part reduced the BP during recovery, and the same occurred after the control session without exercise.

\section{Conclusões}

From the BP values obtained acutely, none of the strength exercise protocols applied showed to be more beneficial or harmful to the cardiovascular system. This study found the different strength exercise protocols applied were not efficient to promote $\mathrm{PEH}$ for up to 30 minutes of recovery in healthy elderly.

\section{Agradecimentos}

PIBIC-CNPq, CAPES, FISEX and LABFEF - FEF, UNICAMP

BOUTOUYRIE, P.; VERMEERSH, S.J.; Determinants of pulse wave velocity in healthy people and in the presence of cardiovascular risk factors: 'establishing normal and reference values'. Eur Heart Jl, v.31, n.19, p.2338-50, 2010.

ACSM. American College of Sports Medicine position stand. Progression models in resistance training for healthy adults. $\mathrm{Med} \mathrm{Sci}$ Sports Exer, v.41, p.687-708, 2009.

MITCHELL, C.J.; CHURCHWARD-VENNE, T.A.; WEST, D.W.; et al. Resistance exercise load does not determine training-mediated hypertrophic gains in young men. J. Appl. physiol. v.113, p.71-77, 2013

LAURENTINO, G.;, UGRINOWITSCH, C.; AIHARA, A.Y.; et al. Effects of strength training and vascular occlusion. Int J Sports Med, v.29, n.8, p.664-7, 2008 